\title{
Stimulant use and stimulant use disorders in Australia: findings from the National Survey of Mental Health and Wellbeing
}

Grant E Sara MM, MM(Psychother) FRANZCP, Clinical Senio Lecturer ${ }^{1,2}$

Philip M Burgess MA, PhD, Professor

Meredith G Harris BA(Hons), MPASR, MPH, Senior Research Fellow

Gin S Malhi MD, FRCPsych, FRANZCP Professor of Psychiatry

Havev A Whitetererd MB BS, MPH, FRANZCP, Kratzmann Professor

Sydney Medical School University of Sydney Sydney, NSW.

2 School of Population Health, Queensland Centre for Mental Health Research,

University of Queensland Brisbane, QLD.

GRSara@nsccahs. health.nsw.gov.au

MJA 2011; 195: 607-610 doi: 10.5694/mjall.10360

Editorial p 565 Research p 610 timulant use in Australia has increased over the past two decades. ${ }^{1,2}$ Regular stimulant use may be associated with serious morbidity. ${ }^{3}$ A balanced policy and service response requires reliable data about stimulant use disorders in the general population.

\section{Estimating rates of stimulant use}

Population surveys are the most frequent method for estimating rates of illicit drug use. In Australia, the 2007 National Drug Strategy Household Drug Survey (NDSHDS) sampled people aged 14 years and over every 3 years from 1993 to $2007 .{ }^{4}$ Over this period, methamphetamine was the most commonly used stimulant, with prevalence of lifetime use averaging $7.4 \%$ (from $5.4 \%$ in 1993 to $9.1 \%$ in 2004). The 2007 NDSHDS reported a significant decline in lifetime amphetamine use (down to 6.3\%) and a steady increase in the lifetime use of ecstasy (3.1\% in 1993 up to $8.9 \%$ in 2007) and cocaine (2.5\% in 1993 up to $5.9 \%$ in 2007). Rates of recent (12-month) use were about a third of lifetime rates and followed a similar trend over time. Prevalence of recent methamphetamine use was 2.3\% in 2007 (down from $3.7 \%$ in 1998). Recent ecstasy and cocaine use increased steadily to 2007 (ecstasy 3.5\%, cocaine 1.6\%).

Differences in methodology make direct comparison difficult, but rates of stimulant use in Australia appear consistent with or slightly higher than those reported in population surveys in the United States, ${ }^{5,6}$ Canada, $^{7}$ the United Kingdom ${ }^{8}$ and New Zealand. ${ }^{9}$

\section{Rates of stimulant use disorder}

In Australia, the prevalence of stimulant use disorders has been estimated by indirect methods. McKetin and colleagues $^{10}$ used multipliers from regular amphetamine users in Sydney and benchmark data for substance treatment, admissions and arrests in 2002-2003.

Abstract

Objectives: To describe the prevalence of lifetime and 12-month stimulant use disorders in the Australian population, and to compare the prevalence estimates from a population survey with prevalence estimates derived using indirect methods.

Design and setting: Data were drawn from the 2007 National Survey of Mental Health and Wellbeing, which sampled 8841 residents of private dwellings in Australia in 2007. Interviews were conducted by lay interviewers using the Composite International Diagnostic Interview.

Main outcome measures: Lifetime and 12-month rates of stimulant use and stimulant use disorders (abuse, dependence) diagnosed according to the Diagnostic and statistical manual of mental disorders, 4th edition.

Results: Lifetime prevalence of stimulant use disorders was 3.3\%, and 12-month prevalence was $0.6 \%$, equating to more than 97000 Australians. Nearly half of those who had used stimulants on more than five occasions met criteria for a lifetime disorder. More than $8 \%$ of men aged 16-29 years met criteria for a lifetime stimulant use disorder. Prevalence estimates were consistent with recent estimates using indirect methods.

Conclusions: Stimulant use disorders affect a significant number of Australians, and are most common in the age groups at greatest risk for development of psychosis.

Both survey and indirect methods have limitations in estimating the prevalence of stimulant use disorders. Population surveys may underestimate prevalence as they sample conventional households, underrepresent "hotspots" and high-risk subgroups, and may be sensitive to stigma. ${ }^{10}$ Indirect methods use samples of identified substance users such as treatment populations. They may overrepresent more disadvantaged users and underrepresent employed users who are not in contact with treatment services. Rates of help-seeking may differ by age, sex or cultural background. ${ }^{10}$ Therefore, it is useful to compare prevalence estimates using both direct and indirect methods.

Harm associated with stimulant use does not affect all users. It is associated with higher frequency of use, higher potency forms and riskier routes of administration such as intravenous injection. ${ }^{1}$ Stimulant users who have features of a stimulant use disorder (abuse or dependence) are at highest risk. Therefore, "we need to know the size of the population of dependent methamphetamine users in order to understand their impact on public health and order, and to estimate the services that are needed to reduce this impact". ${ }^{10}$
Compared with estimates of stimulant use in the general population, less is known about rates of stimulant use disorder. In the early 1980s, the US Epidemiological Catchment Area Study reported lifetime prevalence of dependence on or abuse of amphetamines $(1.7 \%)$ and cocaine $(0.2 \%){ }^{11}$ However, no recent population surveys have reported prevalence of stimulant dependence using standardised diagnostic criteria. In the UK, the National Health Service National Substance Use Survey ${ }^{8}$ reported rates of "stimulant dependence", but this is based on a single positive answer to a screening questionnaire. Teesson and colleagues $^{12}$ compared data from the US National Comorbidity Survey (1990-1996) and the Australian National Survey of Mental Health and Wellbeing (NSMHW) of 1997 and found 12-month prevalence of stimulant use disorders of $0.2 \%$ in the US and $0.5 \%$ in Australia. However, to allow comparison of the two surveys, these figures excluded cocaine.

The 1990-1996 US National Comorbidity Survey ${ }^{13}$ and its 2001-2003 replication ${ }^{14}$ report only cocaine and prescription stimulants. The International Consortium on Psychiatric Epidemiology ${ }^{15}$ reported lifetime use of cocaine and stimulants, but not rates 
1 Lifetime use of individual stimulant drugs, per 100 population - National Survey of Mental Health and Wellbeing 2007

\begin{tabular}{lcc} 
Stimulant & $\begin{array}{c}\text { At any time } \\
(95 \% \mathrm{Cl})\end{array}$ & $\begin{array}{c}\text { More than } 5 \text { times } \\
(95 \% \mathrm{CI})\end{array}$ \\
\hline Amphetamine/speed & $9.3(8.6-10.0)$ & $5.4(4.7-6.1)$ \\
Methamphetamine/base/ice & $3.0(2.6-3.4)$ & $1.9(1.6-2.3)$ \\
Ecstasy & $7.9(7.1-8.7)$ & $4.5(3.9-5.2)$ \\
Cocaine & $5.2(4.5-5.9)$ & $2.8(2.2-3.4)$ \\
Any & $12.2(11.5-12.9)$ & $7.2(6.5-8.0)$
\end{tabular}

of abuse or dependence. The World Health Organization World Mental Health Survey Initiative studies ${ }^{15-19}$ reported use of alcohol or any illicit drug but did not describe specific drug classes or diagnoses of abuse or dependence. The New Zealand Mental Health Survey ${ }^{20}$ and national household surveys of drug use ${ }^{9}$ did not report stimulant use disorders.

\section{National Survey of Mental Health and Wellbeing}

The 2007 NSMHW collected information on substance use and substance use disorders. $^{21}$ It provides the only population data on stimulant (amphetamine, ecstasy and cocaine) use disorders in Australia diagnosed according to standardised diagnostic criteria.

Our study examines the prevalence of lifetime and 12-month stimulant use and disorders (including amphetamine-type stimulants, ecstasy and cocaine) in the Australian population in 2007, based on NSMHW data. It also compares estimates from a population survey with previous estimates derived using indirect methods.

\section{Methods}

The 2007 NSMHW was a nationally representative household survey conducted in 2007 by the Australian Bureau of Statistics (ABS). ${ }^{21}$ Slade and colleagues ${ }^{22}$ provide a detailed description of its methodology. The population scope was usual residents of private dwellings in Australia, aged 16 to 85 years. A stratified, multistage probability sample of dwellings (excluding very remote areas) was selected by the ABS. Interviewers used household composition questions to identify eligible adults in each household. One person in each household was randomly selected to be interviewed. Younger (16-24 years) and older (65-85 years) people were oversampled. In total, 8841 respondents from 14805 eligible households completed the interview (a response rate of $60 \%$ ). Interviews were conducted in English by trained interviewers, and took an average of 90 minutes to complete.

\section{Stimulant use variables}

The NSMHW asked about stimulant use in five categories: (i) amphetamine/speed, (ii) methamphetamine/ base/ice, (iii) ecstasy, (iv) cocaine, and (v) any stimulant. Lifetime stimulant use was assessed by asking whether respondents had used any of these drugs (i) at any time, and (ii) more than five times in their lifetime. Respondents who reported lifetime stimulant use on more than five occasions were asked whether they had used any stimulant in the past 12 months.

\section{Diagnostic variables}

The NSMHW used a modified Composite International Diagnostic Interview. $^{23}$ This provides lifetime and 12 month diagnoses of stimulant abuse and stimulant dependence. The NSMHW reported ICD-10 (International Classification of Disease, 10th revision) ${ }^{24}$ and DSM-IV (Diagnostic and statistical manual of mental disorders, 4th edition) ${ }^{25}$ diagnoses. For consistency with recent studies of the prevalence of cannabis and other substances, DSM-IV criteria and hierarchy rules were used in this study.

\section{Data analysis}

Data from the 2007 NSMHW Basic Confidentialised Unit Record File $(\mathrm{CURF})^{26}$ were analysed using PASW Statistics, version 18 (SPSS Inc, Chicago, Ill, USA), and Stata, version 11 (StataCorp, College Station, Tex, USA). Data were weighted using the factors within the CURF, which adjust for the differential probability of survey selection and for the age and sex distribution of the Australian population. ${ }^{22}$ Standard errors and 95\% confidence intervals (CIs) were calculated using jackknife repeated replication to take account of the complex survey design.

Prevalence was calculated for the whole NSMHW age range (16-85 years). For comparison with indirect estimates, ${ }^{10}$ prevalence was also cal- culated for persons aged 16-49 years only. Following ABS conventions, estimates with a relative standard error of between $25 \%$ and $50 \%$ were considered possibly unreliable. Estimates with a relative standard error greater than $50 \%$ were suppressed.

\section{Results}

\section{Prevalence}

The prevalence of lifetime stimulant use was $12.2 \%$ ( $7.2 \%$ on more than five occasions). Amphetamine/speed was the most commonly used stimulant $(9.3 \%$ any use; $5.4 \%$ more than five occasions), followed by ecstasy $(7.9 \% ; 4.5 \%)$, cocaine $(5.2 \% ; 2.8 \%)$, and methamphetamine/base/ice (3.0\%; 1.9\%) (Box 1). Overall 12month use of any stimulant was $3.9 \%$.

Lifetime and 12-month prevalence of DSM-IV stimulant use disorders are shown in Box 2. Lifetime prevalence of stimulant use disorders was $3.3 \%$, with abuse $(1.9 \%)$ more common than dependence $(1.4 \%)$. The 12 -month prevalence of stimulant use disorders was $0.61 \%$ (abuse, $0.35 \%$; dependence, $0.26 \%$ ), equating to more than 97000 Australians.

For people aged 16-49 years, 12month stimulant use disorder rates were higher (any disorder, 0.97\%; abuse, $0.55 \%$; dependence, $0.43 \%$ ).

Of the $7.2 \%$ of people who had used stimulants on more than five occasions, nearly half $(46 \%$, or $3.3 \%$ of the population) met criteria for a lifetime stimulant use disorder.

Prevalence of stimulant use disorders by age group and sex are shown in Box 3. Stimulant use disorders were more common in men (lifetime, $4.6 \%$; 12 month, $0.9 \%$ ) than women (lifetime, $2.1 \%$; 12 -month, $0.3 \%$ ). Stimulant use disorders declined with age, with the highest rate in people aged $16-29$ years (lifetime, $7.0 \%$; 12-month, 1.6\%). The highest prevalence rates were among men aged 16-29 years (lifetime, 8.4\%; 12-month, 2\%). Estimates were unreliable for some groups with lower rates.

\section{Discussion}

This study provides the only current estimate of the prevalence of diagnosed stimulant use disorders in a large population sample. 
Our findings are consistent with indirect estimates. McKetin and colleagues $^{10}$ used 2002-2003 data to estimate 12-month prevalence of dependant amphetamine use among 15-49-year-olds as between $0.6 \%$ and $1.1 \%$. For people aged 16-49 years, we found a 12-month prevalence of $0.97 \% \quad(95 \%$ CI, $0.66 \%-$ $1.29 \%$ ). A population survey may be expected to produce a lower prevalence estimate than indirect methods based on drug-using populations.

Stimulant use is more common in younger adults and men. 4,6,7,27 We found a similar pattern for stimulant use disorders; more than $8 \%$ of men aged 16-29 years met criteria for a lifetime stimulant use disorder. Younger men are the group most vulnerable to the development of psychosis. This finding is of concern given that stimulants may interact with other risk factors in the development of psychosis.

Population-based studies are likely to underestimate prevalence of the use of illicit drugs, for reasons discussed above. The NSMHW was designed primarily for the study of high prevalence mental health and substance use conditions. Disorders of relatively low prevalence such as stimulant use disorders are at the lower limits of resolution of the NSMHW, especially when considering 12-month prevalence rates. This means that there are higher levels of uncertainty in the estimates of prevalence, particularly when examining subgroups by age or sex. The response rate for the 2007 survey was lower than that for the 1997 survey, and this may have introduced a selection or sampling bias that may account for some differences from other surveys.

More than $12 \%$ of Australians over 16 have used illicit stimulants. Of those using stimulants on more than five occasions, nearly half met criteria for a lifetime substance use disorder. Although 12-month prevalence of stimulant use disorders was less than $1 \%$, this represents nearly 100000 Australians. Men aged 18-29 years had the highest prevalence rates, with $8.4 \%$ having a lifetime stimulant use disorder and $2.0 \%$ having a 12 -month disorder. It follows that stimulant use disorders are most common in people in the age groups most vulnerable to the development of psychosis.

2 Lifetime and 12-month prevalence of stimulant use and stimulant use disorder,* per 100 population National Survey of Mental Health and Wellbeing 2007

12-month

\begin{tabular}{lccc} 
Stimulant use/disorder & Lifetime $(95 \% \mathrm{Cl})$ & Aged 19-85 years $(95 \% \mathrm{Cl})$ & Aged 16-49 years $(95 \% \mathrm{Cl})$ \\
\hline Abuse & $1.93(1.57-2.29)$ & $0.35(0.21-0.49)$ & $0.55(0.32-0.78)$ \\
Dependence & $1.41(0.92-1.91)$ & $0.26(0.12-0.41)$ & $0.43(0.19-0.66)^{\dagger}$ \\
Any stimulant use disorder & $3.34(2.76-3.93)$ & $0.61(0.41-0.81)$ & $0.97(0.66-1.29)$ \\
Stimulant use without disorder & $3.90(3.36-4.45)$ & $3.30(2.70-3.90)$ & - \\
\hline
\end{tabular}

* Diagnostic and statistical manual of mental disorders, 4 th ed. ${ }^{25} \dagger$ Relative standard error of estimate between $25 \%$ and $50 \%$ : estimate may be unreliable.

\section{Competing interests: No relevant disclosures.}

Received 27 Mar 2011, accepted 29 Aug 2011.

1 Degenhardt L, Roxburgh A, BlackE, et al. The epidemiology of methamphetamine use and harm in Australia. Drug Alcohol Rev 2008; 27: 243-252.

2 Ministerial Council on Drug Strategy. National Amphetamine-Type Stimulant Strategy 2008-2011. Canberra: Australian Government, 2008.

3 Darke S, Kaye S, McKetin R, Duflou J. Major physical and psychological harms of amphetamine use. Drug Alcohol Rev 2008; 27: 253-262.

4 Australian Institute of Health and Welfare. 2007 Drug Strategy Household Survey: detailed findings. Canberra: AlHW, 2008. (AlHW Cat. No. PHE 107; Drug Statistics Series No. 22.)

5 Substance Abuse and Mental Health Services Administration. National Survey on Drug Use and Health. The NSDUH report: methamphetamine use Rockville, Md: Office of Applied Studies, 2007.

6 Substance Abuse and Mental Health Services Administration. Results from the 2009 National Survey on Drug Use and Health: Vol. I. Summary of national findings. Rockville, Md: Office of Applied Studies, 2010.

7 Adlaf E, Begin P, Sawka E, editors. Canadian Addiction Survey (CAS): a national survey of Canadians' use of alcohol and other drugs: prevalence of use and related harms: detailed report. Ottowa: Canadian Centre on Substance Abuse, 2005

8 Coulthardt M, Farrell M, Singleton N, Meltzer H. Tobacco, alcohol and drug use and mental health. London: TSO, 2002.

9 Wilkins C, Sweetsur P. Trends in population drug use in New Zealand: findings from national household surveying of drug use in 1998, 2001, 2003, and 2006. N Z Med J 2008; 121: 61-71.

10 McKetin R, McLaren J, Kelly E, et al. Estimating the number of regular and dependent methamphetamine users in Australia. Technical Report No. 230. Sydney: National Drug and Alcohol Research Centre, 2005.

11 Regier DA, Farmer ME, Rae DS, et al. Comorbidity of mental disorders with alcohol and other drug abuse JAMA 1990: 264: 2511-2518.

12 Teesson M, Baillie A, Lynskey M, et al. Substance use, dependence and treatment seeking in the United States and Australia: a cross-national comparison. Drug Alcohol Depend 2006; 81: 149-55.

13 Kessler RC, Aguilar-Gaxiola S, Berglund PA, et al. Patterns and predictors of treatment seeking after onset of a substance use disorder. Arch Gen Psychiatry 2001; 58: 1065-1071.

14 Degenhardt L, Chiu WT, Sampson N, et al. Epidemiological patterns of extra-medical drug use in the United States: evidence from the National Comorbidity Survey Replication, 2001-2003.Drug Alcohol Depend 2007: 90: 210-223.

15 Vega WA, Aguilar-Gaxiola S, Andrade L, et al. Prevalence and age of onset for drug use in seven international sites: results from the international consortium of psychiatric epidemiology.Drug Alcohol Depend 2002; 68: 285-297.

16 Gureje O, Lasebikan VO, Kola L, Makanjuola VA. Lifetime and 12-month prevalence of mental disorders in the Nigerian Survey of Mental Health and Well-Being. Br J Psychiatry 2006; 188: 465-471.
3 Lifetime and 12-month prevalence of stimulant use disorder,* per 100 population, by sex and age group National Survey of Mental Health and Wellbeing 2007

Women $(95 \% \mathrm{Cl}) \quad$ Men $(95 \% \mathrm{Cl}) \quad$ All $(95 \% \mathrm{Cl})$

\begin{tabular}{|cccc}
\hline Lifetime & & & \\
\hline $16-29$ years & $5.5(3.7-7.3)$ & $8.4(4.7-12.1)$ & $7.0(4.9-9.2)$ \\
30-39 years & $2.7(1.3-4.0)^{\dagger}$ & $7.2(4.9-9.6)$ & $4.9(3.5-6.3)$ \\
$\geqslant 40$ years & $0.5(0.2-0.7)^{\dagger}$ & $2.1(1.3-2.8)$ & $1.3(0.8-1.7)$ \\
All ages & $2.1(1.6-2.6)$ & $4.6(3.6-5.7)$ & $3.3(2.8-3.9)$ \\
12-month & & & \\
$16-29$ years & $1.1(0.3-1.9)^{\dagger}$ & $2.0(1.0-3.0)$ & $1.6(1.0-2.2)$ \\
$30-39$ years & $\mathrm{s}$ & $1.1(0.1-2.1)^{\dagger}$ & $0.7(0.1-1.2)^{\dagger}$ \\
$\geqslant 40$ years & $\mathrm{s}$ & $\mathrm{s}$ & $\mathrm{s}$ \\
All ages & $0.3(0.1-0.5)$ & $0.9(0.6-1.3)$ & $0.6(0.4-0.8)$ \\
\hline
\end{tabular}

* Diagnostic and statistical manual of mental disorders, 4th ed. ${ }^{25}$ tRelative standard error of estimate (RSE) between 25\% and 50\%: estimate may be unreliable. $s=$ Estimate suppressed as RSE $>50 \%$.

17 Jacobi F, Wittchen HU, Holting C, et al. Prevalence, comorbidity and correlates of mental disorders in the general population: results from the German Health Interview and Examination Survey (GHS). Psychol Med 2004; 34: 597-611.

18 Lee S, Tsang A, Zhang MY, et al. Lifetime prevalence and inter-cohort variation in DSM-IV disorders in metropolitan China. Psychol Med 2007; 37: 61-71.

19 Stein DJ, Seedat S, Herman A, Moomal H, Heeringa SG, Kessler RC, et al. Lifetime prevalence of psychiatric disorders in South Africa. Br J Psychiatry 2008; 192: $112-117$.

20 Wells JE, Baxter J, Schaaf D, editors. Substance use disorders in Te Rau Hinengaro: the New Zealand Mental Health Survey. Wellington: Alcohol Advisory Council of New Zealand, 2006.

21 Australian Bureau of Statistics. National Survey of Mental Health and Wellbeing: summary of results, 2007. Canberra: ABS, 2008. (ABS Cat. No. 4326.0.)

22 Slade T, Johnston A, Oakley Browne MA, et al. 2007 National Survey of Mental Health and Wellbeing: methods and key findings. Aust N Z J Psychiatry 2009; 43: 594-605.

23 World Health Organization. Composite international diagnostic interview. Geneva: WHO, 1997.

24 World Health Organization. International classification of diseases and related health problems, 10th revision (ICD-10). 2nd ed. Geneva: WHO, 1992.

25 American Psychiatric Association. Diagnostic and statistical manual of mental disorders. 4th ed. Text revision. Washington, DC: APA, 2000.

26 Australian Bureau of Statistics. Technical manual: National Survey of Mental Health and Wellbeing, Confidentialised Unit Record Files 2007. Canberra: ABS, 2009. (ABSCat. No. 43290.)

27 Degenhardt L, Coffey C, Carlin JB, et al. Who are the new amphetamine users? A 10 -year prospective study of young Australians. Addiction 2007; 102 1269-1279. 